\title{
ANÁLISE DA CAPACIDADE FISCAL PER CAPITA NA DESCENTRALIZAÇÃO DO PROGRAMA SEGUNDO TEMPO/ME JUNTO AOS MUNICÍPIOS
}

\author{
ANALYSIS OF MUNICIPAL GOVERNMENTS' PER CAPITA TAX CAPACITY FOR \\ DECENTRALIZATION OF PROGRAM SEGUNDO TEMPO
}

\author{
ANÁLISIS DE LA CAPACIDAD FISCAL POR HABITANTE EN LA \\ DESCENTRALIZACIÓN DEL PROGRAMA SEGUNDO TIEMPO/ME JUNTO A LOS \\ MUNICIPIOS
}

\section{Edmilson Santos dos Santos ${ }^{\star}$, Fernando Augusto Starepravo**}

Palavras chave: Política pública. Esportes. Descentralização. Orçamento.

\begin{abstract}
Resumo: Um dos constrangimentos que dificultariam a implementação de programas que exigem contrapartida é a capacidade fiscal das prefeituras. Nesse sentido, este estudo teve como objetivo verificar se a capacidade fiscal per capita é um fator relevante na distribuição do Programa Segundo Tempo (PST) do Ministério do Esporte. As informações sobre a capacidade fiscal foram coletadas no IBGE, e sobre o programa diretamente do site do PST. Foram analisados os dados referentes ao período que vai de 2003 a 2012. Os resultados apontam que a capacidade fiscal (CF) per capita não interferiu na distribuição do PST. Além disso, não foi possível confirmar a hipótese de que a CF per capita diminui a capacidade de descentralização do programa.
\end{abstract}

Abstract: One of the constraints hampering implementation of programs that demand a counterpart contribution would be the tax capacity of municipal governments. Therefore, this study aims to verify whether per capita tax capacity is a factor in the distribution of the Ministry of Sports' Program Segundo Tempo (PST). Information on tax capacity was collected from IBGE's website and while data on the Program itself was collected from its own website. We analyzed Data on 2003-2012. Results show that per capita tax capacity did not interfere on PST distribution. In addition, the hypothesis that per capita tax capacity decreases the ability to decentralize the program could not be confirmed.

Resumen: Una de las limitaciones que dificultan la aplicación de programas que requieren una contrapartida es la capacidad fiscal de las municipalidades. Por ello, este estudio tuvo como objetivo verificar si la Capacidad Fiscal por habitante es un factor relevante en la distribución del Programa Segundo Tiempo (PST) del Ministerio de Deportes. Las informaciones sobre la Capacidad Fiscal se recogieron en el IBGE, y sobre el programa directamente desde la web del PST. Se analizaron los datos referentes al período que va de 2003 a 2012. Los resultados muestran que la Capacidad Fiscal por habitante no afectó a la distribución del PST. Además, no fue posible confirmar la hipótesis de que la Capacidad Fiscal disminuye la capacidad de descentralización del programa.
*Universidade Federal do Vale do São Francisco. Petrolina, PE. Brasil. E-mail: edmilson.santos@univasf. edu.br

**Universidade Estadual de Maringá. Maringá, PR. Brasil.

E-mail: fernando.starepravo@ hotmail. com

Recebido em: 06-03-2017 Aprovado em: 25-11-2017

DOI: https://doi.org/10.22456/1982-8918.71700 (c) (1) (8) Licence 


\section{INTRODUÇÃO}

Passados mais de dez anos de implementação do Programa Segundo Tempo (PST) do Ministério do Esporte (ME), destinado a fomentar o esporte educacional, alguns trabalhos têm sido produzidos buscando fazer a avaliação nacional do programa. Castro (2016), Almeida e Marchi Jr. (2010), Athayde, Mascarenhas e Salvador (2015) analisaram aspectos associados ao financiamento do programa; Santos (2016), a participação dos governos estaduais na descentralização do PST; Reverdito et al. (2016), a descentralização do programa por níveis de desenvolvimento humano (IDH); Santos, Souza Neto e Starepravo (2015) avaliaram o vazio assistencial produzido pelo programa na Região Nordeste; Santos, Andrade e Santos (2014), a participação das prefeituras da descentralização do PST, a descentralização do programa junto aos municípios vulneráveis; Santos (2013) analisou a participação das variáveis institucionais na difusão do PST; e Santos (2012), a descentralização politicamente motivada do programa. A avaliação do desempenho do programa já entrou na agenda dos analistas de políticas públicas de esporte no Brasil. No entanto, pouco conhecemos das variáveis que ajudam a explicar o resultado da política.

O PST ${ }^{1}$ foi formulado em 2003, pelo então recém-criado Ministério do Esporte², com objetivo de garantir que crianças e jovens vulneráveis pudessem ter acesso a essa política social. O programa parte da premissa acertada de que há uma distribuição muito desigual das políticas de esporte educacional no Brasil. Essa realidade fica evidente quando analisamos o desempenho do esporte educacional no Perfil dos Municípios Brasileiros de 2003 (IBGE, 2006). Apesar de ficar clara a má distribuição dos equipamentos esportivos, profissionais e políticas públicas entre as regiões, o desempenho global, mesmo nas regiões de maior potencial econômico, apresenta um cenário muito precário.

Sua implementação junto aos municípios e estados brasileiros segue a dinâmica de descentralização por oferta. O governo federal (a União) produz a política e oferta no "mercado", buscando atrair atenção dos agentes implementadores (governos estaduais, municipais e terceiro setor), ou seja, o Ministério do Esporte oferta o programa através de edital e os interessados concorrem ${ }^{3}$. Aqueles contemplados estabelecem parceria com o governo federal para sua implementação.

A autonomia política dos entes federados não permite impor uma determinada política pública a outros entes da escala subnacional (estados e municípios) (ARRETCHE; VAZQUEZ; GOMES, 2012). A indução à cooperação é realizada através da oferta de incentivos ${ }^{4}$ à

1 Em relação ao PST, conforme Kravchychyn (2014, p. 76) "[...] o direcionamento adotado, em sua essência o PST não representa uma ideia original, mas um realinhamento estratégico do Programa Esporte da Escola (PEE) e do Programa Esporte Solidário (PES), ambos do governo anterior, de Fernando Henrique Cardoso (1995-2002). São, pois, programas que se sucedem originados de projetos políticos distintos, mas que apresentam interseções no momento de transição de governos e da instituição do PST (FERREIRA; CASSIOLATO; GONZALEZ, 2009; OLIVEIRA, 2009; STAREPRAVO, 2011)".

2 Cabe ressaltar que, segundo Starepravo, Mezzadri e Marchi Júnior (2015), o Ministério do Esporte foi criado, principalmente, com vistas à acomodação política de um partido da base aliada do governo do presidente Lula, o PCdoB. A princípio o PCdoB tinha pretensões em assumir preferencialmente o Ministério da Defesa ou o Ministério da Cultura e ainda resistia contra a criação do Ministério do Esporte, almejando um espaço maior ou de mais visibilidade no novo governo. De toda forma, o Ministério do Esporte foi criado, por meio da Medida provisória $\mathrm{n}$. 103 de $1^{0}$ de janeiro de 2003 - convertida na Lei n. 10.683, de 2003, e entregue à administração do PCdoB. O partido, durante o tempo que permaneceu à frente do Ministério do Esporte (2003-14), elegeu o PST como programa prioritário da pasta, com vistas, também, à visibilidade política do partido.

3 Cabe ressaltar que os entes podem ser convidados pelo Ministério do Esporte para desenvolver o Programa, como ocorreu recentemente com o PST - legado dos megaeventos esportivos -, quando os municípios sedes ou aqueles próximos foram chamados a estabelecer convênios com a Pasta.

4 Os incentivos são os elementos que são utilizados para seduzir os potenciais conveniadores. Os principais são a injeção de recursos novos e a não necessidade de se formular um programa (dado que a capacidade técnica é um fator importante à oferta de políticas públicas). Para 
descentralização do programa. Aos interessados cabe a apresentação de proposta e concorrer nos editais lançados pela Secretaria Nacional de Esporte, Educação, Lazer e Inclusão Social do Ministério do Esporte 5 .

Para implementarem o programa, há a previsão de contrapartida que envolve a garantia de recursos por parte da entidade conveniadora. Cabe ressaltar que o percentual da contrapartida é feito a partir dos percentuais definidos na Lei Orçamentária Anual (LOA), considerando uma série de critérios presentes na legislação nacional. Nesse sentido, a capacidade fiscal (CF) dos municípios pode ser uma variável relevante na descentralização do programa junto às prefeituras. É razoável pensarmos que a baixa adesão ao programa se deve às dificuldades fiscais das prefeituras: o PST conveniou com apenas 7,8\% das prefeituras ( $n=435)$ em dez anos de implementação. Todavia, devemos considerar que até 2011 as ONGs foram importantes entidades conveniadoras do PST. Após um escândalo de corrupção envolvendo as ONGs e o PST, passou-se a privilegiar as prefeituras como principais parceiras no desenvolvimento do PST.

Nesse sentido, o presente trabalho analisa o efeito da variável CF per capita dos municípios no desempenho do programa nos dez primeiros anos de implementação. Para tanto, organizamos o trabalho em quatro etapas. Na primeira, buscamos analisar o debate em torno da capacidade fiscal e financiamento de políticas públicas por parte dos municípios. Em seguida, apresentamos o desenho metodológico e a análise dos resultados e por último as considerações finais.

\section{BASE TEÓRICA: DESEMPENHO FISCAL E O FINANCIAMENTO DA POLÍTICA PÚBLICA}

Todas as políticas públicas implicam algum gasto financeiro, mesmo aquelas que envolvem apenas contrapartidas (de recursos humanos ou equipamentos), como é o caso do PST do Ministério do Esporte. A viabilidade econômica do poder executivo não é negligenciável à determinação da capacidade decisória (SOUZA, 2005), à implementação de políticas próprias ou à adesão a programas de entes superiores. Primeiro porque os recursos não são inesgotáveis; em segundo lugar, por conta das assimetrias fiscais (capacidade de arrecadação/ gastos); em terceiro, há despesas que são fixadas pelo marco legal e não podem ser alteradas por ato discricionário do executivo, restringindo sua margem de manobra; e, por último, porque cada área possui uma dotação orçamentária que indica a prioridade de uma dada agenda.

O desequilíbrio fiscal é justificado por Zuccolotto, Ribeiro e Abrantes (2009) como resultado da formação cultural da sociedade brasileira, que historicamente conviveu com a falta de responsabilidade com a gestão fiscal. Conforme Loureiro e Abrucio (2004), os municípios não estavam acostumados com o aumento da eficiência da arrecadação tributária e tampouco eram pressionados pela tecnocracia econômica durante o Regime Militar a terem um comportamento eficiente. Como resultado, temos municípios pouco capacitados para darem respostas efetivas às necessidades da população (CLEMENTINO, 2000). Mas para Afonso e Araújo (2000) essa realidade não pode ser enquadrada simplesmente como descaso dos prefeitos. Fatores administrativos de eficiência e de acesso a informações de qualidade não

\footnotetext{
5 Segundo Starepravo, Mezzadri e Marchi Júnior (2015), o Decreto Federal n. 7.529/2011 alterou a estrutura burocrática do Ministério do Esporte e, entre outras ações, criou a Secretaria Nacional de Esporte, Educação, Lazer e Inclusão Social do Ministério do Esporte, hoje responsável pelo PST. Antes disso o PST ficava a cargo da extinta Secretaria Nacional de Esporte Educacional.
} 
estão ao alcance da burocracia estatal em todos os municípios brasileiros, trazendo impactos à análise da capacidade de financiamento das políticas.

O problema se agravou com a criação de novos municípios sem a devida comprovação de sua viabilidade fiscal. A fragmentação político-administrativa produziu municípios que são incapazes de financiarem suas políticas públicas com recursos próprios (PAES; SIQUEIRA, 2008). Essa diversidade gerou enorme assimetria na disponibilização dos recursos orçamentários (REZENDE, 1997). Ao permitir autonomia fiscal aos municípios ${ }^{6}$, com um aporte de recurso considerável pós-constituição, houve, em algumas realidades, um descontrole das contas públicas que teve impacto na diminuição da capacidade de resposta do poder público frente aos desafios colocados em termos de diminuição das desigualdades. Com isso, houve a suboferta de políticas públicas que comprometeu a descentralização ${ }^{7}$ de políticas em algumas áreas (MORAES, 2006).

Havia uma grande expectativa, gerada por posicionamentos que Afonso e Lobo (1996) apontam como simplistas, de que a descentralização fiscal ${ }^{8}$ permitiria uma maior oferta de recursos em direção às populações mais necessitadas. 0 modelo de descentralização acabou por desnudar seus limites e efeitos não esperados, diminuindo seu poder. Dentre eles, Melo (1996) destaca a existência de uma burocracia de baixa qualificação, o imobilismo por conta da ambiguidade de competência (a aérea esportiva é um caso), a falta de regulamentação do governo central, com perdas visíveis de articulação, e a maior proximidade das elites locais (pressão clientelista).

Affonso (1996) aponta que a descentralização brasileira foi marcada por fortes traços de descoordenação. Aliadas a esse fator estão as zonas cinzentas de responsabilidade descentralização por ausência (ALMEIDA, 1995) e superposições de ações -, que produziram um cenário que diminuiu o potencial equalizador da intervenção estatal na área social.

[...] a descentralização em curso nas áreas sociais analisadas corre o risco de confirmar, quando não de agravar, as disparidades intra e inter-regionais sob o federalismo centralizado. A forma pela qual se tem processado 0 rearranjo de competências, especialmente nos casos de descentralização por ausência, pode neutralizar ou perverter 0 efeito da equidade que toda política social tem por meta (ALMEIDA, 1995, p. 105).

Diante dessa realidade, o grande desafio que se coloca consiste em construir "[...] mecanismos de coordenação descentralizados e democráticos de maneira a enfrentar eficazmente as disparidades sociais que obstaculizam o desenvolvimento em nosso país" (AFFONSO, 1996, p. 9). Nesse caso, o governo federal passa a ocupar um papel estratégico na realocação dos recursos (COSTA, 2010), principalmente na descentralização de programas desenhados e financiados pela esfera federal (como o PST). Para Afonso e Lobo (1996), não há uma fórmula ideal para garantir uma descentralização ótima. 0 mais importante, como sugere Melo (1996, p. 19), é que "a experiência descentralizante num contexto democrático tem permitido [...] um processo de descentralização social em que seus limites e possibilidades podem ser efetivamente compreendidos".

6 Não é condicional às federações garantirem autonomia fiscal aos municípios. Cabe salientar também que dentre as 28 federações somos a única que possui três entes federados (União, estados e Distrito Federal e municípios).

7 A finalidade da descentralização é a oferta de políticas públicas pelo poder político local que tem melhores condições de avaliar as demandas da população. Essa descentralização pode ser feita com o poder local assumindo serviços ou cooperando com algum ente superior para sua implementação, como acontece com o PST.

8 A descentralização fiscal implica garantir aos entes subnacionais ferramentas fiscais para financiarem suas políticas. No caso dos municípios, a Constituição Federal de 1988 garantiu que eles pudessem legislar sobre três impostos: Imposto Predial e Territorial Urbano (IPTU), Imposto sobre Serviço de Qualquer Natureza (ISSQN) e Imposto de Transferência de Bens Imóveis Inter-vivos (ITBI). 
Parte importante das receitas fiscais dos municípios vem de duas fontes: da arrecadação tributária própria e das transferências governamentais. A arrecadação tributária ${ }^{9}$ própria está diretamente associada à dinâmica econômica municipal. Portanto, em municípios onde há menor circulação de riqueza, há também menor ferramenta fiscal para fazer frente às necessidades em termo de políticas públicas. O Imposto sobre Serviços (ISS) está diretamente associado à prestação de serviços cuja dinâmica se dá de uma forma mais encorpada nas cidades mais urbanizadas (ABRÚCIO; COUTO, 1996). Outra fonte de arrecadação importante é o Imposto Predial e Territorial Urbano (IPTU), que possui, como o próprio nome indica, fortes características urbanas. É também o que apresenta maior índice de evasão, apesar dos esforços para aumentar a base tributária. O ITBI está diretamente associado, por um lado, à dinâmica econômica e, por outro, à populacional, e é o que possui menor impacto dentre os tributos municipais.

Como transferência estadual, nós temos o Imposto sobre Circulação de Mercadorias e Prestação de Serviços (ICMS) em que a cota a que cada município tem direito é calculada com base na arrecadação municipal. Dessa forma, municípios menores, com uma dinâmica econômica mais frágil, são os que acabam recebendo menos.

Para garantir maior equilíbrio diante dos desequilíbrios fiscais produzidos pelo modelo de tributação municipal, o Congresso Nacional construiu fonte de recurso para os municípios de caráter redistributivo, o FPM - Fundo de Participação dos Municípios. Essa fonte orçamentária consolidou a descentralização fiscal brasileira (AFONSO; ARAÚJO, 2000) e acabou se tornando a principal fonte de receita dos pequenos municípios (SOUZA, 2004). Por ter sido eminentemente política, definida por um processo constituinte em que o governo federal estava enfraquecido para restringir a descentralização pela demanda, essa fonte de recurso acabou impondo algumas limitações que comprometem maior equilíbrio entre os entes federados (AFONSO; LOBO, 1996).

Alguns estudos têm apontado para diferentes resultados desse processo. Moraes (2006) sugere, com relação às transferências governamentais, duas questões importantes: por um lado, a renda per capita dos municípios menores têm aumentado, ficando acima das metrópoles criando uma severa distorção no princípio redistributivista; por outro, quanto maior a participação no FPM, menor é o esforço fiscal. Meneguin e Bugarin (2001) destacam que 0 aumento das transferências pode, inclusive, aumentar o déficit dos municípios - ampliando as desigualdades -, pois mais recursos podem criar uma ilusão fiscal (flypaper effect). Por conta dessa realidade, Clementino (2000) identifica que não há base teórica nem empírica para afirmar que a descentralização está associada ao aumento da eficiência e da eficácia dos gastos públicos. Por conta das distorções ocorridas da realidade brasileira, Rezende (1997) entende que há uma enorme dificuldade em conciliar descentralização fiscal e desigualdade regional.

Municípios mais vulneráveis acabam sendo dependentes das transferências intergovernamentais e apresentam margem muito restrita para, autonomamente, definir prioridades políticas. Ao analisarem esse contexto, Gomes e Dowell (2000) identificaram que 0 argumento recém-referido não responde de maneira adequada à realidade dos fatos. Ao compararem o PIB de municípios pequenos, de até 5.000 habitantes, identificaram que a renda per capita varia muito. Esse fator gera uma distorção na distribuição dos recursos

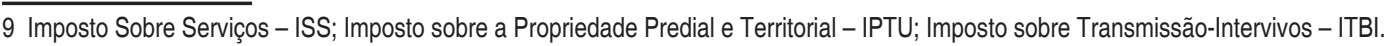


de transferências, causando uma descentralização perversa em que regiões mais populosas e com maior volume de problemas urbanos acabam recebendo uma menor quantidade de recursos quando comparamos às populações vulneráveis. Com isso, um menor esforço fiscal dos pequenos municípios é suportado pelas populações, também vulneráveis, dos municípios maiores. Comparativamente, segundo os autores, são esses os municípios que gastam mais com seus legislativos, o que acaba contribuindo ainda mais para a diminuição dos recursos próprios destinados às políticas públicas.

O governo federal poderá participar, diante das dificuldades de investimentos dos governos municipais, distribuindo recursos, podendo ou não ser casada com funções às instâncias subnacionais, ou garantindo recursos centralizados (como o PST) a programas descentralizados (ALMEIDA, 1995). Ao descentralizar programas o governo federal deve promover maior equilíbrio no acesso às políticas públicas [Inciso III, Art. 3 (BRASIL, 1988)].

O desenho institucional da política pública contribui decisivamente para o desempenho da política. São os incentivos dados que irão balizar a cooperação entre os entes federados e o resultado da ação. Incentivos frágeis promoverão baixa adesão. Eles podem ser adequados/ inadequados ou suficientes/insuficientes ao fim proposto. Um pacote de regras homogêneas sistema de incentivos - não leva necessariamente a resultados igualitários (ARRETCHE, 2010).

Como refere Almeida (1995), na descentralização o resultado final é dependente das disposições políticas, das condições financeiras e administrativas das instâncias subnacionais. Não podemos dispensar também que, em cada área, a mobilização política e os interesses nela engendrados são dotados de um valor que interfere na descentralização. Naqueles programas de maior reconhecimento, que pautam o discurso político, que detêm reconhecimento público como indispensável para o bem-estar ou que possuem fortes grupos de interesse disputando uma determinada compreensão da política, há maior pressão em direção à agenda.

Como se sabe, essa não é uma realidade vivida pelo esporte. Suas pautas (excluídas aqui aquelas destinadas ao esporte rendimento) recebem atenção marginal quanto às políticas sociais ligadas ao esporte e ao lazer, fato registrado amplamente na literatura. Isso pode ser facilmente observado quando se analisam os gastos do governo central (ATHAYDE, MASCARENHAS; SALVADOR, 2015; VERONEZ, 2005).

Tanto para construir políticas próprias como para atender às exigências de convênios é preciso garantir recursos financeiros para a execução das políticas públicas. Nesse caso, a capacidade fiscal dos municípios responde por parte importante do problema. Quando a oferta de recursos é pouca e as demandas são muitas ou variadas, como na área esportiva (educação, lazer e rendimento), ou precisam ser disputadas com outras áreas, aumentam as chances de as diferentes formas de restrições pressionarem a não adesão a programas federais.

\section{DECISÕES METODOLÓGICAS}

O presente trabalho configurou-se como um estudo descritivo de corte quantitativo e teve por objetivo verificar se a CF per capita é um fator interveniente na descentralização do PST quando as entidades conveniadas são as prefeituras. A CF per capita é uma medida que busca identificar a quantidade de recursos disponíveis por habitante com base na arrecadação dos tributos municipais: ISS, IPTU e ITBI (Imposto sobre Transmissão-Intervivos). 0 ano base da arrecadação dos tributos e da população foi 2008 (IBGE). Para essa análise aqui 
empreendida consideraram-se os convênios realizados entre as prefeituras e a Secretaria de Esporte Educacional do Ministério do Esporte entre 2003 e $2012\left(n=435^{10}\right)$.

$O$ critério de análise para essa avaliação foi identificar o Potencial de Convênio (PC) e o Conveniamento Efetivo (CE). O PC indica o percentual de cidades que estão acima da CF per capita mínima conveniada. O CE se refere ao percentual das prefeituras que realizaram convênio no período a partir do corte estabelecido pela CF per capita mínima conveniada. Para análise do CE vamos considerar apenas as cidades que tiveram seus dados tributários disponibilizados.

Tendo em vista a elevada variação da CF entre os 5.570 municípios brasileiros, organizamos os dados de forma a analisar essa realidade a partir da variável tamanho dos municípios (classe populacional do Instituto Brasileiro de Geografia e Estatística - IBGE). A classe populacional foi organizada em cinco grupos: "A", municípios de até 5.000 habitantes; "B", municípios entre 5.001 e 20.000 habitantes; "C", municípios entre 20.001 e 50.000 habitantes; "D", municípios entre 50.001 e 100.000 habitantes; "E", acima de 100.001 habitantes.

O banco de dados contém informações de diferentes fontes: a) a relação dos municípios, dos tributos municipais (IPTU, ISS e ITBI) e da população foi buscada diretamente no site do IBGE (IBGE, 2016); b) a distribuição dos municípios por nível de IDH foi capturada diretamente no site do Programa das Nações Unidas para o Desenvolvimento (PNUD) (PNUD, 2016); c) do Ministério do Esporte foram coletadas diretamente do site da instituição (BRASIL, 2016), as informações relativas às prefeituras que estabeleceram convênio no período de 2003 a 2012. Utilizaram-se a estatística descritiva para análise dos dados e o software SPSS (Statistical Package for the Social Science) versão 17.0 como instrumento de análise.

\section{DISCUSSÃO E ANÁLISE DOS RESULTADOS}

O resultado da descentralização via oferta de serviços pelo governo federal aos agentes descentralizadores está associada à quantidade de recursos disponíveis para 0 programa (CASTRO, 2016), seus incentivos à descentralização e o interesse dos agentes descentralizadores ${ }^{11}$. Uma avaliação precisa do interesse dos agentes descentralizadores depende do número de participantes concorrentes aos editais do PST. Apesar de importante, essa análise escapa ao escopo desse trabalho.

A quantidade de recursos disponibilizados depende da prioridade do programa dentro das ações do Ministério do Esporte (CASTRO, 2016). Porém, compreendendo que outras instituições, como governos estaduais e terceiro setor, foram parceirass do governo federal na descentralização do PST, consideramos que o papel desempenhado pelos municípios estava associado ao grau de prioridade dado por eles à descentralização do programa.

Observando a participação das prefeituras na descentralização do PST no período, é possível constatar que o programa teve enormes dificuldades para obter a cooperação dos governos municipais. Em dez anos apenas 435 prefeituras (7,8\%) conveniaram-se com 0 Ministério do Esporte para implementar o programa. Um resultado que coloca em xeque a pretensão do governo federal de democratizar o acesso ao desporto educacional via PST - mas

10 Importante salientar que uma prefeitura pode ter realizado mais de um convênio durante o período.

11 A participação dos governos estaduais e do terceiro setor não permite analisar a descentralização do programa em direção às prefeituras, pois essas duas instituições poderiam implementar núcleos em mais de uma cidade. Portanto, a localização geográfica, principalmente do segundo, não garante precisão no aspecto aqui observado. 
compatível com a estrutura do modelo federalista brasileiro e muito próximo da descoordenação destacada por Afonso (1996).

No período não houve uma política direcionada à ampliação da participação das prefeituras na descentralização do PST. Ele inicia em 2003 com três convênios firmados com prefeituras e chega em 2012 com apenas oito. Foi no ano de 2005 que o programa obteve 0 melhor resultado, 115 prefeituras (2\%) descentralizaram o PST. O segundo melhor resultado foi em 2008, 104 prefeituras. Como pode ser percebido, houve uma distribuição instável do programa (ATHAYDE; MASCARENHAS; SALVADOR, 2015) que comprometeu seriamente sua capilarização no território nacional.

Já em relação à CF per capita dos municípios:

Tabela 1 - Variação da CF per capita por classe populacional.

\begin{tabular}{lccc}
\hline \multicolumn{1}{c}{ Classe Pop. } & № & Mínimo (R\$) & Máximo (R\$) \\
\hline Até 5.000 & 1.268 & 0,07 & $5.386,74$ \\
5.001 a 20.000 & 2.674 & 0,24 & $2.009,08$ \\
20.001 a 50.000 & 1.037 & 0,31 & $1.688,43$ \\
50.001 a 100.000 & 308 & 0,60 & 985,56 \\
Acima 100.001 & 276 & 0,13 & $1.537,09$ \\
\hline \multicolumn{4}{c}{ Fonte: Os autores (2017). }
\end{tabular}

Em todas as classes populacionais há enorme variação da CF per capita entre as prefeituras, como pode ser observado na Tabela 1, demonstrando que elas possuem condições muito diferenciadas de financiamento de suas políticas públicas. A maior disparidade se dá nos municípios de até 5.000 habitantes, os mais frágeis.

Para 0 ano de 2008 nem todas as prefeituras disponibilizaram os valores referentes à arrecadação da tributação própria. Essa lacuna criou um problema na leitura dos dados. Para avaliar o PC consideramos dois cenários. No primeiro, estão todas as prefeituras que se conveniaram com o Ministério do Esporte, independentemente de terem seus dados tributários disponibilizados, desde que haja uma prefeitura que se conveniou com o programa. No segundo, as prefeituras que tiveram seus dados tributários disponibilizados.

Tabela 2 - Potencial de convênio das prefeituras por classe populacional.

\begin{tabular}{|c|c|c|c|c|c|c|}
\hline \multirow[b]{2}{*}{ Classe Pop. } & \multirow[b]{2}{*}{ № } & \multicolumn{2}{|c|}{$100 \%$ dos municípios* } & \multicolumn{3}{|c|}{ Municípios com informações tributárias } \\
\hline & & $\begin{array}{l}\text { CF per capita } \\
\text { mínima }\end{array}$ & $\mathrm{PC}(\%)$ & № & $\begin{array}{l}\text { CF per capita } \\
\text { mínima }\end{array}$ & PC (\%) \\
\hline Até 5.000 & 1.268 & 0,07 & $100^{*}$ & 1.179 & 7,98 & 99,66 \\
\hline 5.001 a 20.000 & 2.674 & 0,24 & $100^{*}$ & 2.385 & 4,20 & 98,15 \\
\hline 20.001 a 50.000 & 1.037 & 0,51 & $100^{*}$ & 918 & 0,98 & 99,78 \\
\hline 50.001 a 100.000 & 308 & 0,60 & $100^{*}$ & 308 & 0,60 & 100 \\
\hline Acima 100.001 & 276 & 0,13 & $100^{*}$ & 255 & 11,57 & 98,43 \\
\hline
\end{tabular}

A primeira observação diz respeito ao primeiro cenário colocado na Tabela 2; mesmo as prefeituras que não tiveram seus dados tributários disponibilizados fizeram convênios com 
o Ministério do Esporte para descentralizarem o PST. Elas estão em todas as classes de população e representam $9,31 \%(n=518)$ do total. Isso indica que para a descentralização do PST o fator econômico não interfere na implementação, contrariando a literatura que coloca a viabilidade financeira como fator decisivo à descentralização (SOUZA, 2005).

No segundo cenário, onde está a grande maioria dos convênios com o PST, também é possível observar que a CF per capita mínima incorpora a grande maioria dos municípios, independentemente da classe populacional. O menor desempenho incorpora $98,15 \%$ dos municípios. Considerando o critério utilizado para avaliar a capacidade de conveniamento com o Ministério do Esporte, é possível afirmar que a CF per capita não é fator que constrange as prefeituras a participarem dos editais do programa. Portanto, a CF per capita não interfere na descentralização do PST, contrariando as ponderações realizadas por Ferreira, Cassiolato e Gonzalez (2009).

O CE acaba por desnudar as fragilidades da política, como pode ser observado na tabela abaixo. Com a CF per capita não sendo fator inibidor de participação no programa, o baixo conveniamento indica, de certa forma, o fracasso dos incentivos e da forma de qualificação das propostas. Matias (2013) já havia chamado atenção para esse problema. Mesmo reconhecendo que o sistema de incentivos não leva a resultados igualitários (ARRETCHE, 2010), não podemos dispensar o papel estratégico do governo federal na realocação dos recursos em direção aos mais vulneráveis (COSTA, 2010). A baixa adesão dos municípios de menor classe populacional, onde estão as cidades mais vulneráveis, indica que há um problema também no desenho do programa. Seus incentivos não são suficientes para atrair atenção desses atores. Por outro lado, abre-se um campo de pesquisa que pode comprovar ou não essa tese, considerando outras variáveis como: o limite orçamentário das prefeituras, a participação das entidades do terceiro setor no desenvolvimento do programa, a falta de capacidade técnica dos recursos humanos das prefeituras para produzir projetos e concretizar convênios, o excesso de burocracia para celebrar convênios, entre outros.

Tabela 3 - Conveniamento Efetivo das prefeituras por classe populacional.

\begin{tabular}{lccc}
\hline \multirow{2}{*}{ Classe Pop. } & № & \multicolumn{2}{c}{ Convênio do PST } \\
\cline { 3 - 4 } & & № & \% \\
\hline Até 5.000 & 1.179 & 50 & 5,24 \\
5.001 a 20.000 & 2.385 & 138 & 9,15 \\
20.001 a 50.000 & 918 & 84 & 13,31 \\
50.001 a 100.000 & 308 & 41 & 40,78 \\
Acima de 100.001 & 255 & 104 & \\
\hline
\end{tabular}

Fonte: Os autores (2017).

Os piores resultados estão justamente entre as cidades de menor classe populacional, as mais fragilizadas em termos de capacidade de financiamento das políticas públicas (SILVA, 2007). O dado mais preocupante é que os melhores resultados se dão junto às cidades maiores (que estão em menor número na federação). Isso aponta para a direção de que o tamanho do município é uma variável que interfere na descentralização do PST e não a CF per capita.

Considerando o objetivo do PST de democratizar o esporte educacional, os resultados aqui encontrados demonstram que o desenho do programa (os incentivos à descentralização) 
e sua capacidade de financiamento não garantem sua consecução. A contrapartida exigida pelo programa não impede que municípios mais pobres possam descentralizar o programa, aspecto importante a ser valorizado.

\section{CONCLUSÃO}

Pós-redemocratização, o PST é o mais importante programa criado pelo governo federal para fomentar o esporte educacional (SANTOS; SOUZA NETO; STAREPRAVO, 2015; KRAVCHYCHYN, 2014). Portanto, sua iniciativa dá um passo adiante no processo de fortalecimento das políticas sociais. No entanto, a participação das prefeituras aponta que os incentivos ofertados não são suficientes para atrair a atenção dos gestores locais, mesmo considerando as demais variáveis que podem influenciar no baixo número de conveniamentos, como o limite orçamentário das prefeituras, a participação das entidades do terceiro setor no desenvolvimento do programa, a falta de capacidade técnica dos recursos humanos das prefeituras para produzir projetos e concretizar convênios, o excesso de burocracia para celebrar convênios. Para um programa que se coloca na esteira da descentralização das atividades de esporte educacional, atender em dez anos apenas 435 prefeituras indica que há um problema no desenho do programa para atrair esses atores.

A hipótese de que a CF per capita era fator que constrangia a participação das prefeituras na adesão ao PST não restou confirmada. Considerando a questão fiscal, o PST não cria nenhum problema à participação de qualquer uma das prefeituras brasileiras. Portanto, seu desenho está adequado à democratização do esporte educacional. O problema reside nos incentivos (a falta de) à descentralização por parte das prefeituras.

Não deixa de ser importante salientar que as maiores lacunas de acesso ao esporte educacional se dão nos municípios menores, mas são os maiores que obtêm vantagem no conveniamento; fator esse já destacado por Matias (2013). A descentralização do esporte educacional implica a garantia desse tema na agenda das prefeituras. A baixa capilaridade do programa junto a esses atores impede que essa agenda possa ser difundida e valorizada.

Como política social, o PST tem como um dos objetivos diminuir a desigualdade de acesso ao esporte educacional. Porém, como ficou claro no estudo, a implementação do programa criou ilhas de privilégios. Isso não constitui uma anormalidade, como destacam Arretche e Marques (2007), Arretche (2004) e Souza e Carvalho (1999), uma vez que a descentralização de políticas não significa necessariamente diminuição das desigualdades.

\section{REFERÊNCIAS}

ABRUCIO, Fernando L.; COUTO, Cláudio G. A redefinição do papel do Estado no âmbito local. São Paulo em Perspectiva, n. 10, v. 3, p. 40-47, 1996.

AFFONSO, Rui. Os municípios e os desafios da federação no Brasil. São Paulo em Perspectiva, n. 10, v. 3, p. 3-10, 1996. 
AFONSO, José R. R.; ARAUJO, Erika A. A capacidade de gastos dos municípios brasileiros: arrecadação própria e receita disponível. Caderno Adenauer, n. 4, p. 35-55, 2000.

AFONSO, José R. R.; LOBO, Thereza. Descentralização fiscal e participação em experiências democráticas retardatárias. Planejamento e Políticas Públicas, n. 14, p. 3-36, 1996.

ALMEIDA, Bárbara S.; MARCHI Jr., Wanderley. O financiamento dos programas federais de esporte e lazer no Brasil (2004 a 2008). Movimento, n. 4, v. 16, p. 73-92, out./dez. 2010.

ALMEIDA, Maria Hermínia T. Federalismo e políticas sociais. Revista Brasileira de Ciências Sociais, v. 10, n. 28, p. 88-108, 1995.

ALMEIDA, Maria Hermínia T. Federalismo e políticas sociais. Revista Brasileira de Ciências Sociais, v. 10, n. 28, p. 88-108, 1995.

ARRETCHE, Marta. Federalismo e igualdade territorial: uma contradição em termos? Dados, v. 53, n. 3, p. 587- 620, 2010.

ARRETCHE, Marta. Federalismo e políticas sociais no Brasil: problemas de coordenação e autonomia. São Paulo em Perspectiva, v. 18, n. 2, p. 17-26, 2004.

ARRETCHE, Marta; MARQUES, Eduardo. Condicionantes locais da descentralização das políticas de saúde. In: HOCHMAN, G.; ARRETCHE, M.; MARQUES, E. (Orgs.). Políticas Públicas no Brasil. Rio de Janeiro: Ed. FIOCRUZ, p. 207-244, 2007.

ARRETCHE, Marta; VAZQUEZ, Daniel, GOMES, Sandra. Descentralização e autonomia: deslocando os termos do debate. In: LAVALLE, A. G. (Org.). 0 Horizonte da política: questões emergentes e agendas de pesquisa. São Paulo: UNESP, 2012.p 29-62.

ATHAYDE, Pedro; MASCARENHAS, Fernando; SALVADOR, Evilásio. Primeiras aproximações de uma análise do financiamento da política nacional de esporte e lazer no Governo Lula.

Revista Brasileira de Ciências do Esporte, v. 37, n. 1, p. 2-10, 2015.

BRASIL. Constituição da República Federativa do Brasil de 1988, de 05 de outubro de 1988. Brasília, 1988. Disponível em: < http://www.planalto.gov.br/ccivil03/constituicao/ constitui\%C3\%A7ao.htm>. Acesso em: 30 jan. 2017.

BRASIL. Ministério do Esporte. Disponível em: $<$ http://www.esporte.gov.br>. Acesso em: 1‥ out. 2016.

CASTRO, Suelen B. E. de. Políticas públicas para o esporte e lazer e o ciclo orçamentário brasileiro (2004-2011): prioridades e distribuição de recursos durante os processos de elaboração e execução orçamentária. 2016. 382 f. Tese (doutorado) - Universidade Federal do Paraná, Setor de Ciências Biológicas, Programa de Pós-Graduação em Educação Física: Curitiba, 2016.

CLEMENTINO, Maria do Livramento M. Finanças públicas no nível local de governo. Caderno Metrópole, n. 4, p. 159-182, 2000.

COSTA, Valeriano Mendes F. C. Federalismo e relações intergovernamentais: implicações para a reforma da educação no Brasil. Educação e Sociedade, v. 13, n. 112, p. 729-748, jul./set. 2010.

FERREIRA, Hélder; CASSIOLATO, Martha; GONZALEZ, Roberto. Uma experiência de desenvolvimento metodológico para avaliação de programas: o modelo lógico do Programa Segundo Tempo. Brasília, DF: IPEA, 2009. (Texto para Discussão n. 1369). 
GOMES, Gustavo M.; DOWELL, Maria Cristina. Descentralização política, federalismo fiscal e criação de municípios: o que é mau para o econômico nem sempre é bom para o social. Brasília, DF: IPEA, 2000. (Texto para Discussão, n. 706).

IBGE. Instituto Brasileiro de Geografia e Estatística. Disponível em: <http://www.ibge.gov.br/ home/>. Acesso em: 02 out.2016.

IBGE. Instituto Brasileiro de Geografia e Estatística. Perfil dos municípios brasileiros, esporte 2003. Disponível em: <http://www.ibge.gov.br/home/estatistica/economia/perfilmunic/esporte2003/>. Acesso em: 5 mar.2016.

KRAVCHYCHYN, Claudio. Projetos e programas sociais esportivos no Brasil: histórico, estado da arte e contribuições do Programa Segundo Tempo. 2014. 177f. Tese (Doutorado) Programa de Pós-Graduação em Educação Física, Universidade Estadual de Maringá, 2014.

LOUREIRO, Maria Rita; ABRUCIO, Fernando L. Política e reformas fiscais no Brasil recente. Revista Economia Política, v. 24, n. 1, p. 50-72, jan./mar. 2004.

MATIAS, Wagner B. A política esportiva do governo Lula: o Programa Segundo Tempo. Licere, v. 16, n. 1, p. 1-23, 2013.

MELO, Marcus A. Crise federativa, guerra fiscal e "hobbesianismo municipal" efeitos perversos da descentralização? São Paulo em Perspectiva, n. 10, v. 3, p. 11-20, 1996.

MENEGUIN, Fernando B.; BUGARIN, Maurício S. Reeleição e política fiscal: um estudo dos efeitos da reeleição nos gastos públicos. Economia Aplicada, v. 5, n. 3, p. 600-622, jul./dez. 2001.

MORAES, David P. de. Arrecadação tributária municipal: esforço fiscal, transferências e Lei de Responsabilidade Fiscal. 2006. 45 f. Dissertação (Mestrado em Escola de Administração). Fundação Getúlio Vargas, São Paulo, 2006.

PAES, Nelson L.; SIQUEIRA, Marcelo L. Desenvolvimento regional e federalismo fiscal no Brasil: em busca da igualdade na distribuição de receitas. Economia Aplicada, v. 12, n. 4, p. 707-742, out./dez. 2008.

PNUD. Programa das Nações Unidas para o Desenvolvimento. Disponível em: <http://www. br.pnud.org/>. Acesso em: 30 out. 2016.

REVERDITO, Riller S. et al. O Programa Segundo Tempo (PST) em municípios brasileiros: indicadores de resultado no macrossistema. Journal of Physical Education, v. 27, n. 1, p. 2754, 2016.

REZENDE, Flávio da C. Descentralização, gastos públicos e preferências alocativas dos governos locais no Brasil. Dados, v. 40, n. 3, p. 413-440, 1997.

SANTOS, Edmilson S. dos. Ambiente institucional e difusão do Programa Segundo Tempo: uma análise da difusão regional de 2005 a 2009. Pensar a Prática, v. 16, n.1, p. 35-53, 2013.

SANTOS, Edmilson S. dos. As coalizões e os partidos políticos na difusão do Programa Segundo Tempo. Licere, v. 15, n. 3, p. 1-26, 2012.

SANTOS, Edmilson S. dos. Governo do estado e descentralização Programa Segundo Tempo. Pensar a Prática, v. 19, n. 2, p. 398-406, 2016. 
SANTOS, Edmilson S. dos; ANDRADE, Jean Carlo; SANTOS, Roberto S. dos. Programa Segundo Tempo e o papel das prefeituras em sua difusão. Pensar a Prática, v. 17, n. 4, p. 3642, 2014.

SILVA, A.L.A. A mecânica do laço enforcado: municipalismo, federalismo fiscal e políticas públicas: gestão de políticas sociais no Brasil. In: FAHEL Murilo; NEVES, Jorge Alexandre Barbosa (Orgs.). Gestão de políticas sociais no Brasil. Belo Horizonte: PUC Minas, 2007. p. 179-191.

SOUZA NETO, Marina S.; SANTOS, Edmilson S.; STAREPRAVO, Fernando A. Programa Segundo Tempo e o vazio assistencial na Região Nordeste. Movimento, v. 21, n.3, p. 759-771, 2015.

SOUZA, Celina. Federalismo, desenho constitucional e instituições federativas no Brasil Pós1998. Revista Sociologia e Política, n. 24, p. 105-121, jun. 2005.

SOUZA, Celina. Governos locais e gestão de políticas sociais universais. São Paulo em Perspectiva v. 18, n. 2, p. 27-41, 2004.

SOUZA, Celina; CARVALHO, Inaiá M. M. Reforma do Estado, descentralização e desigualdades. Lua Nova, n. 48, p. 187-211, 1999.

STAREPRAVO, Fernando A.; MEZZADRI, Fernando M.; MARCHI JUNIOR, Wanderley. Criação e mudanças na estrutura do Ministério do Esporte do Brasil: tensões nas definições de espaços. Revista Brasileira de Educação Física e Esporte, v. 29, n. 2, p. 217-228, jun. 2015.

VERONEZ, Luiz Fernando Camargo. Quando o Estado joga a favor do privado: as políticas de esporte após a Constituição de 1988. 2005. 376f. Tese (Doutorado em Educação Física) Faculdade de Educação Física, Universidade Estadual de Campinas, Campinas, 2005.

ZUCCOLOTTO, Robson; RIBEIRO, Clarice P. de P.; ABRANTES, Luiz A. O comportamento das finanças públicas municipais nas capitais dos estados brasileiros. Reflexão Contábil, v. 28, n. 1, p. 54-69, 2009. 


\section{Apoio financeiro:}

Ministério do Esporte, por meio da Rede Cedes. 